Pengembangan Rekayasa dan Teknologi, Vol 16, No. 1, Juni 2020, pp 17-22

p-ISSN: $1410-9840$ \& e-ISSN: $2580-8850$

http://journals.usm.ac.id/index.php/jprt/index

\title{
Analisa dan Penerapan Metode Neural Networks Dalam Mengidentifikasi Faktor-Faktor Masa Tunggu Kerja Lulusan
}

\author{
Khoirudin, Soiful Hadi, Atmoko Nugroho \\ ${ }^{123}$ Fakultas Teknologi dan Informasi Universitas Semarang \\ ${ }^{1}$ khoirudin@usm.ac.id, ${ }^{2}$ soiful@usm.ac.id, ${ }^{3}$ atmoko@usm.ac.id
}

\begin{abstract}
Abstrack
Tracer Study (TS) atau yang disebut studi pelacakan merupakan penelurusan lulusan yang terkait dengan informasi kompentensi pendidikan tinggi di lingkungan dunia kerja professional yang dapat dilakukan paling cepat 2 tahun setelah wisuda, Tracer Study bertujuan untuk mengetahui outcomes pendidikan dalam bentuk transisi dari dunia pendidikan tinggi ke dunia kerja. Masa tunggu kerja merupakan hal yang sangat penting bagi alumni sebuah perguruan tinggi, hal ini juga termasuk indikator sukses tidaknya pelaksanaan belajar mengajar. Data masa tunggu kerja dapat diperoleh dari data tracer study, tetapi perlu dilakukan penelitian lebih lanjut faktor-faktor apa saja yang mempengaruhi alumni untuk memperoleh pekerjaan pertamanya secara cepat.

Melihat fakta akan pentingnya masa tunggu kerja bagi alumni, peneliti merasa perlu melakukan penelitian untuk mencari penyebab / faktor-faktor apa saja yang mempengaruhi alumni memperoleh pekerjaan pertamanya, dalam penelitian ini peneliti menggunakan metode neural network. Metode ini bekerja dengan cara melakukan training $70 \%$ dan testing $30 \%$ dari data alumni yang baru lulus.

Berdasarkan hasil dari eksperimen dengan metode Neural Network diperoleh hasil class precision sebesar $87.76 \%$. Dan prediksi masa tunggu mendapatpekerjaan $<=6$ Bulan sebesar 43 dan masa tunggu $>6$ bulan sebesar 6 .
\end{abstract}

Keyword: Tracer Study, Neural Network, Masa Tunggu Lulusan

\section{Pendahuluan}

Tracer Study (TS) disebut juga studi pelacakan ialah penelurusan lulusan yang berkaitan dengan informasi tentang kompentensi hasil pendidikan tinggi pada lingkungan dunia kerja professional. Tracer Study berfungsi untuk menilai antara relevansi pendidikan tinggi, informasi kebutuhan dunia industri, dan kelengkapan bagi persyaratan akreditasi pendidikan tinggi. Tracer Study ditujukan untuk lulusan / alumni perguruan tinggi setelah dua tahun (2 tahun) masa kelulusan (survey pertama) dan akan dilanjutkan pada survei kedua yaitu pada tahun kelima (ke-5) setelah mahasiswa tersebut lulus.

Tracer Study bertujuan untuk mengetahui outcomes pendidikan suatu perguruan tinggi dalam bentuk transisi dari dunia pendidikan tinggi ke dalam dunia kerja, output pendidikan yaitu penilaian diri terhadap penguasaan dan pemerolehan kompetensi, selama proses pendidikan didalam perguruan tinggi berupa evaluasi proses pembelajaran dan kontribusi pendidikan tinggi terhadap pemerolehan kompetensi tersebut[1][2], apakah perguruan tinggi berperan dalam peningkatan kualitas mahasiswa terutama outcame atau hasil pembelajaran, serta input pendidikan berupa penggalian informasi lebih lanjut terhadap informasi biografis lulusan[3]. Disamping digunakan untuk keperluan akreditasi, tracer study digunakan juga oleh Ditjen Dikti Kemristekdikti sebagai alat monitoring adaptasi lulusan seuatu perguruan tinggi di Indonesia ketika memasuki dunia kerja[4].

Universitas semarang (USM) merupakan salah satu perguruan tinggi swasta favorit di semarang, dalam 3 tahun terakhir setiap semesternya rata-rata USM meluluskan lebih dari 1500 mahasiswa (sumber UCAC USM). Pada tahun ajaran Ganjil 2018/2019 Jumlah wisudawan USM sebesar 1752 mahasiswa, dan 1650 wisudawan ditahun ajaran Genap 2018/2019. Tentunya berdasarkan data di atas terdapat penambahan jumlah wisudawan di semester ini. Hal ini tentu menjadi tantangan bagi USM untuk melihat hasil pembelajaran yang telah dilakukan pada perguruan tinggi dan diterapkan kedunia kerja, 
Pengembangan Rekayasa dan Teknologi, Vol 16, No. 1, Juni 2020, pp 17-22

p-ISSN: $1410-9840$ \& e-ISSN: $2580-8850$

http://journals.usm.ac.id/index.php/jprt/index

apakah alumni tersebut mendapat pekerjaan yang sesuai dengan pendidikan atau tidak, berapa lamakah alumni (masa tunggu kerja) untuk mendapatkan pekerjaan pertama.

Data mining merupakan metode yang tepat untuk membantu melakukan evaluasi hasil belajar mahasiswa, yang dalam hal ini adalah tracer study. Ada beberapa penelitian yang sudah mencoba untuk membahas tentang tema ini dengan memanfaatkan data mining dan dapat mengklasifikasikan data mahasiswa yang tepat waktu dan tidak[2]-[4].

\section{Landasan Teori}

\subsection{Data Mining}

Data mining merupakan proses ekstraksi (penggalian data) yang sebelumnya belum diketahui, tetapi dapat dipahami, bermanfaat serta dapat digunakan sebagai suatu pengambilan keputusan bisnis yang sangat penting [5]. Data mining disebut juga dengan "Data atau knowledge discovery" atau menemukan sebuah pola tersembunyi yang terdapat pada data [6]. Data mining dimaknai dengan proses menambang pengetahuan (ekstraksi) yang dibutuhkan yang berasal dari data yang jumlahnya besar [7].

\subsection{Neural Network}

Neural Network masuk dalam kategori ilmu Soft Computing. Konsep Neural Network ialah mengadopsi kemampuan otak manusia yang mampu memberikan rangsangan (stimulasi), melakukan proses dan memberikan output. Output ini berasal dari variasi stimulasi dan proses yang terjadi di dalam otak manusia, kemampuan manusia dalam mengolah informasi adalah hasil kompleksitas proses yang terjadi di dalam otak manusia[8].

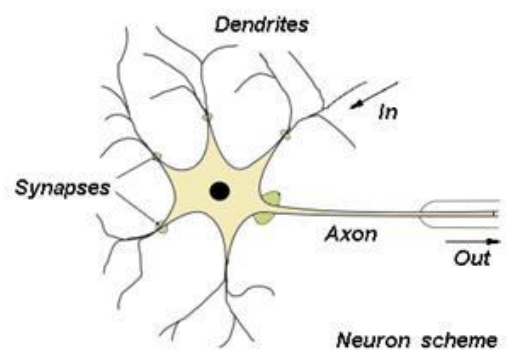

Gambar 1 Struktur Neuron pada otak manusia

\subsection{Struktur Neural Network}

Berdasarkan struktur neuron pada otak manusia, dan proses kerja yang dijelaskan di atas, maka konsep dasar pembangunan neural network buatan (Artificial Neural Network) terbentuk. Konsep dasar dari Artificial Neural Network (ANN) ialah mengadopsi mekanisme pola fikir sebuah sistem yang serupa dengan otak manusia, seperti halnya untuk pemrosesan berbagai sinyal elemen yang diterima, toleransi terhadap kesalahan, maupun parallel processing.

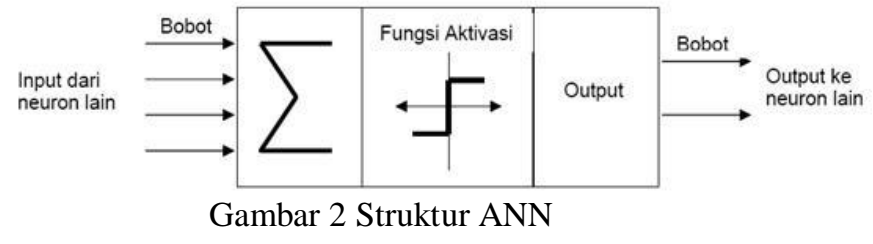

\section{Metodologi Penelitian}

\subsection{Metode Pengumpulan Data}

Dalam penelitian ini data yang peneliti gunakan untuk membangun aplikasi didapat dengan cara wawancara dan observasi dokumen alumni Universitas Semarang yang kami peroleh dari USM Career And Alumni Center Universitas Semarang.

\subsection{Penentuan Variabel Prediksi}

Variable prediksi adalah jumlah alumni, lama waktu study, IPK, kemampuan bahasa asing, Jenis kelamin dan kemampuan softskill, adapun detail variable prediksi dibahas pada sub bab 3.1 Tahap Pre Processing.

\section{Hasil}

\subsection{Tahap Pre Processing}

Dalam penelitian ini data yang digunakan adalah data alumni universitas semarang yang didapat dari USM Career and Alumni Centre, dengan total data 169 data dan terdapat 29 kriteria yang meliputi : 1. Jenis kelamin (jk), 2. IPK, 3. pengetahuan umum $(\mathrm{k} 1)$, 4. keterampilan internet (k2), 5. keterampilan computer $(\mathrm{k} 3), 6$. berpikir kritis (k4), 7. keterampilan riset (k5), 8. kemampuan belajar (k6), 9. kemampuan berkomunikasi (k7), 10. bekerja di bawah tekanan (k8), 11. manajemen waktu 
Pengembangan Rekayasa dan Teknologi, Vol 16, No. 1, Juni 2020, pp 17-22

p-ISSN: $1410-9840$ \& e-ISSN: $2580-8850$

http://journals.usm.ac.id/index.php/jprt/index

(k9), 12. bekerja secara mandiri (k10), 13. bekerja dalam tim (k11), 14. kemampuan dalam memecahkan masalah (k12), 15. negosiasi (k13), 16. kemampuan analisis (k14), 17. toleransi (k5), 18. kemampuan adaptasi (k16), 19. loyalitas dan integritas (k17), 20. bekerja dengan orang yang berbeda budaya maupun latar belakang (k118), 21. kepemimpinan (k19), 22. kemampuan dalam memegang tanggung jawab (k20),

23. Inisiatif (k21), 24. manajemen proyek / program(k22), 25. Kemampuan untuk mempresentasikan ide / produk / laporan(k23), 26. kemampuan dalam menuliskan laporan, memo dan dokumen(k24), 27. kemampuan untuk terus belajar sepanjang hayat (k25), 28. kemampuan bahasa asing Anda pada saat mahasiswa lulus dari perguruan tinggi(k26). Adapun rincian data sebagai berikut.

Table 1. Data penelitian

\begin{tabular}{|c|c|c|c|c|c|c|c|c|c|c|c|c|c|c|c|c|c|c|c|c|c|c|c|c|c|c|c|c|c|c|}
\hline & & & $j a$ & & \begin{tabular}{|l|}
$\mathrm{K} 2$ \\
\end{tabular} & & \begin{tabular}{|l|l} 
K4 \\
\end{tabular} & K5 & K6 & & \begin{tabular}{l|l} 
K8 & 1 \\
\end{tabular} & 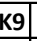 & \begin{tabular}{l|l} 
K10 \\
\end{tabular} & K11 & \begin{tabular}{|l|} 
K12 \\
\end{tabular} & K13 & K14 & K15 & K16 & \begin{tabular}{|l|} 
K17 \\
\end{tabular} & K18 & K19 & K20 & K21 & K22 & K23 & K24 & K25 & K26 & MT \\
\hline 3111 & & $\mathrm{r}-19$ & $r-19$ & 4 & & & 4 & 3 & & & & & & & & & & & & & & & & & & & & 1 & & \\
\hline & & & & 5 & 5 & & 5 & & & & 3 & & & & & & & & & & & & & & & & & & & \\
\hline & & & & 5 & s & & 5 & & & & & & & & & & & & & & & & & & & & & & & \\
\hline & & & & 3 & tra & & trat & & & & 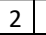 & & & & & & & & & & & & & & & & & & & \\
\hline & & & & 5 & 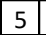 & & 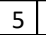 & & & & 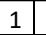 & & & & & & & & & & & & & & & & & & & \\
\hline & & & 3 & 4 & 4 & 4 & 4 & 4 & 4 & 4 & $3+3$ & & & & & & & & & & & & & & & & & & & \\
\hline & & 9 & & 4 & & & 3 & & 3 & & 3 & & & & & & & & & & & & & & & & & & & \\
\hline & & 8 & & 5 & s & & 4 & 4 & 4 & 4 & 4 & & & & & & & & & & & & & & & & & & & \\
\hline & & & 6 & 4 & 5 & 4 & 4 & 4 & 5 & 4 & $-5+2>$ & & & & & & & & & & & & & & & & & & & 12 \\
\hline & 8 & & & 4 & 4 & 4 & 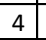 & 4 & 4 & 4 & 4 & 4 & & & & & & & & & & & & & 4 & & 4 & & & - \\
\hline & 3.1 & & & 4 & 1 & & 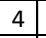 & 4 & 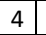 & & 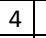 & & & & & & & & & & & & & & & & & & & 8 \\
\hline & & & 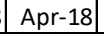 & 3 & $a_{0}$ & 4 & 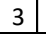 & 3 & $\pi$ & & 3 & & & & & & & & & & & & & & & & & & & 2 \\
\hline & & & & 4 & $172+2+3$ & 4 & 4 & 7 & 4 & 4 & 4 & & & & & & & & & & & & & & & & & & 2 & 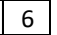 \\
\hline & 1 & & & 5 & 5 & 5 & 5 & 5 & 5 & 5 & 5 & & & & & & & & & & & & & & & & & & 4 & 12 \\
\hline $21111008 /$ & & Feb-16 & May-16 & 3 & 4 & & 4 & & 4 & & 4 & & & & & & & & & & & & & & & & 4 & & 3 & \\
\hline
\end{tabular}

Sedangkan data yang dijatikan output adalah lama waktu tunggu (MT) lulusan Universitas semarang dalam memperoleh pekerjaan pertama. Lama waktu memperoleh pekerjaan dibagi menjadi 3 kategori sebagai berikut

Table 2. kategori lama tunggu

\begin{tabular}{|l|l|l|}
\hline NO & Lama Waktu Tunggu & kategori \\
\hline 1 & $1-6$ Bulan & Masa tunggu $<=6$ Bulan \\
\hline 2 & $>6$ Bulan & Masa tunggu $>$ Bulan \\
\hline
\end{tabular}

Dengan demikian akan terdapat 28 Neuron pada input layer dan 1 neuron pada output layer, dari data yang diperoleh nanti sebanyak 116 Data akan digunakan sebagai data pelatihan dan 50 data akan digunakan sebagai data pengujian. Dalam penelitian ini menggunakan algoritma backpropagation. Pada kasus ini digunakan 1 lapisan hidden layer dengan jumlah neuron pada hidden layer adalah 4 buah. Berikut adalah data sample beserta kategori masa tunggunya. 
Pengembangan Rekayasa dan Teknologi, Vol 16, No. 1, Juni 2020, pp 17-22

p-ISSN: 1410-9840 \& e-ISSN: 2580-8850

http://journals.usm.ac.id/index.php/jprt/index

Table 3. Tabel data sample berserta kategori masa tunggu lulusan

\begin{tabular}{|c|c|c|c|c|c|c|c|c|c|c|c|c|c|c|c|c|c|c|c|c|c|c|c|c|c|c|c|c|c|c|c|}
\hline NIM & $k$ & us & kerja & $K 1$ & K2 & K3 & K4 & K5 & K6 & K7 & K8 & K9 & K10 & K11 & K12 & K13 & K14 & K15 & K16 & K17 & K18 & K19 & K20 & K21 & K22 & K23 & K24 & K25 & $K 26$ & MT & Keterangan \\
\hline B11 & 5 & & & 4 & $I_{1}$ & 1 & 4 & 3 & 4 & 3 & 5 & 4 & 5 & 4 & 4 & a & 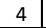 & 5 & 5 & 5 & 4 & 4 & 4 & 5 & 5 & 5 & 5 & 4 & 3 & 1 & Maca Tungau \\
\hline & 3 & 8 & & 5 & 5 & & & 5 & & & & & & & & & & & & & & & & & & & & & & & \\
\hline & & & & 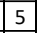 & 5 & & & 5 & & & 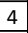 & & & & & & & & & & & & & & & & & & & & \\
\hline & & & $8-18$ & 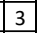 & 4 & & 4 & 3 & & & & & & & & & & & & & & & & & & & & & & & \\
\hline & & & 8 & 5 & 5 & & 5 & 4 & 5 & 5 & & 5 & & 2 & & & & & & & & & & & & & & & & 3 & \\
\hline & 6 & -18 & -18 & 4 & 4 & 4 & 4 & 4 & 4 & 4 & 3 & 5 & & 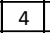 & & & & & & & & & & & & & & & & & \\
\hline & 3 & & 9 & 4 & 4 & & 3 & 3 & 3 & 3 & & 3 & & & & & & & & & & & & & & & & & & & \\
\hline & 2 & & -19 & 5 & 4 & 4 & 4 & 4 & 4 & 4 & 4 & 4 & 5 & 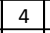 & & & 4 & & & & 4 & -7 & & & 4 & & & 5 & 3 & 7 & n \\
\hline & 3 & -15 & g-16 & 4 & 5 & & 4 & 4 & 5 & 4 & & 4 & $<$ & 2 & & & & & & & & & & & & & & & & 2 & \\
\hline & 8 & -17 & g-17 & 4 & 4 & 4 & 4 & 4 & 4 & 4 & 4 & 4 & 2 & 4 & & & 4 & 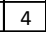 & & & & & & & & & & 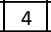 & & & \\
\hline & & 6 & $v-16$ & 4 & 4 & 4 & 4 & 4 & 4 & 4 & 4 & 4 & 4 & 3 & & & 4 & 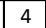 & & & 4 & & & 3 & 4 & & & 4 & 3 & 8 & \\
\hline & 6 & $b-18$ & Apr-18 & 3 & 4 & T & 3 & 3 & 3 & 3 & 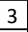 & 3 & 3 & 4 & & & 3 & 3 & & & 3 & 3 & & 4 & & & & 4 & 3 & 2 & ulan \\
\hline & t & $b-18$ & Aug-18 & 4 & 4 & 4 & 4 & 4 & 4 & 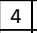 & 4 & 4 & & & & & & & & & & & & & & & & & & & ulan \\
\hline & 2.0 & Mar-19 & Mar-20 & 5 & 5 & 5 & 5 & 5 & 5 & 5 & 5 & 5 & 5 & 5 & & & 5 & 5 & & & 5 & 5 & & & 5 & & & 5 & 4 & 12 & \\
\hline 211110087 & 3.2 & Feb-16 & May-16 & 3 & 4 & 4 & 4 & 3 & 4 & 3 & 4 & 4 & 4 & J & 4 & 2 & 4 & 3 & 4 & & 3 & 2 & 3 & $\mathrm{~J}$ & 3 & & 4 & 4 & 3 & 3 & Bulan \\
\hline
\end{tabular}

\subsection{Pembagian Data}

Pada penelitian data dibagi menjadi 2, yaitu sebesar $70 \%$ sebagai data training dan $30 \%$ sebagai data testing.

\subsection{Implementasi Algoritma}

Dalam penelitian ini data diolah dengan aplikasi rapid miner dengan hasil sebagai berikut :

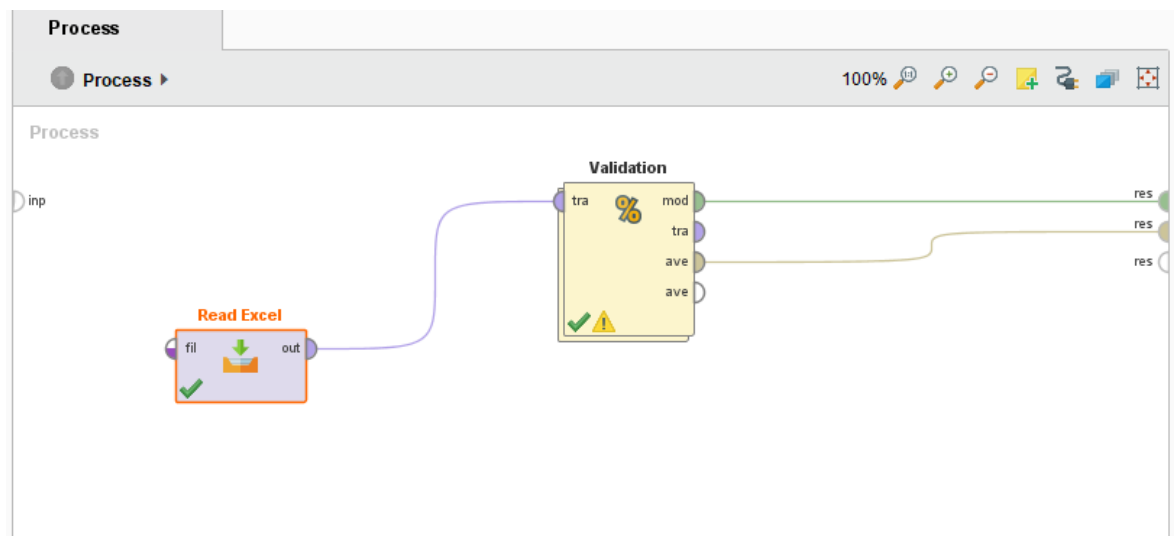

Gambar 3. Desain Proses Sistem

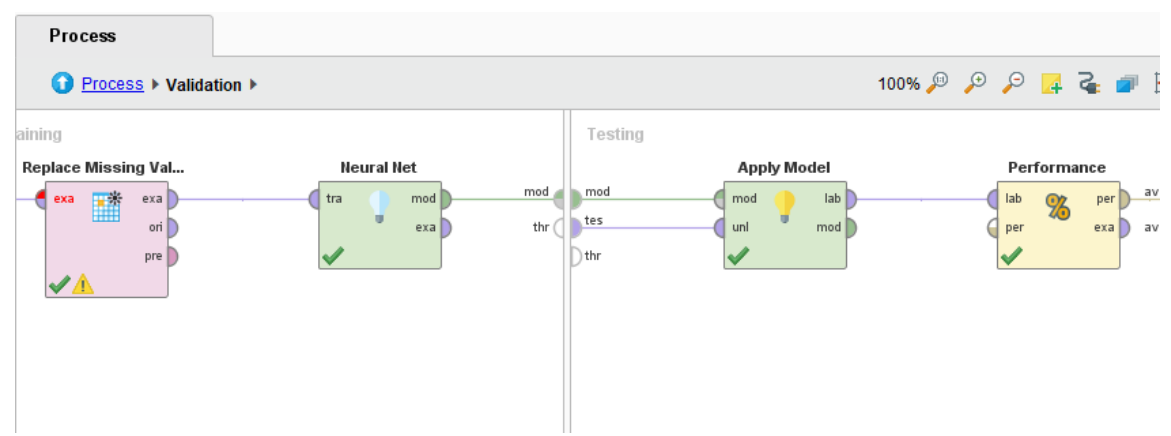

Gambar 4. Penerapan Metode, Apply Model dan Performance

Hasil dari proses data dapat dilihat pada gambar berikut: 
Pengembangan Rekayasa dan Teknologi, Vol 16, No. 1, Juni 2020, pp 17-22

p-ISSN: $1410-9840$ \& e-ISSN: $2580-8850$

http://journals.usm.ac.id/index.php/jprt/index

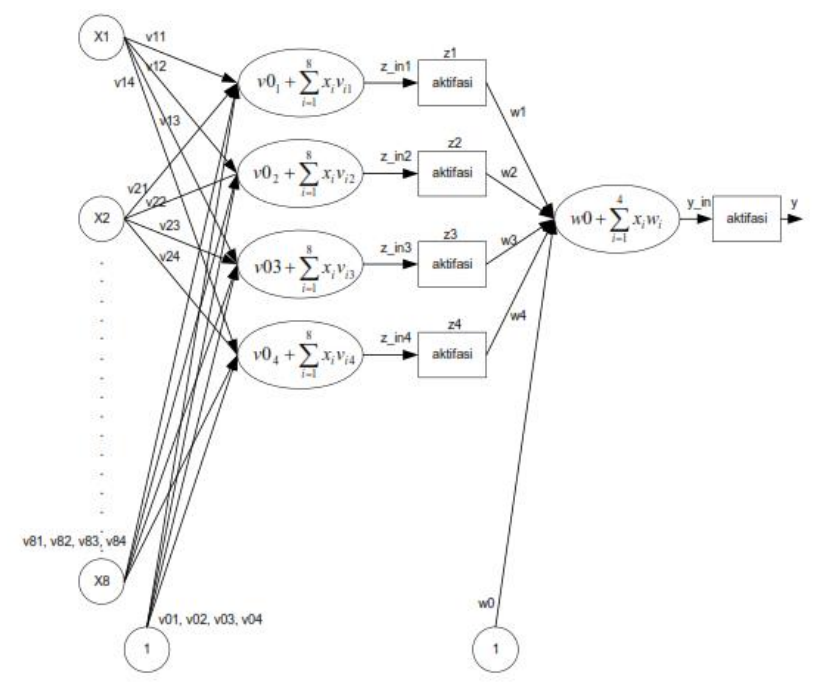

Gambar 1. Arsitektur jaringan backpropagation untuk deteksi waktu tunggu lulusan

4.4 Model Neural Network

Penelitian menggunakan metode eksperimen. Sehingga, untuk mencapat akurasi yang tinggi dan error yang paling diperlukan uji coba. Pada penelitian accuracy: $\mathbf{8 7 . 7 6 \%}$

\begin{tabular}{|l|l|l|l|}
\hline & true Masa Tunggu $<=6$ Bulan & true Masa Tunggu $>6$ Bulan & class precision \\
\hline pred. Masa Tunggu $<=6$ Bulan & 43 & 6 & $87.76 \%$ \\
\hline pred. Masa Tunggu $>6$ Bulan & 0 & 0 & $0.00 \%$ \\
\hline class recall & $100.00 \%$ & $0.00 \%$ & \\
\hline
\end{tabular}

Gambar 2. Hasil akurasi pengolahan data ini epoch, learning rate, momentum yang digunakan adalah default. 1000 epoch, 0.2 learning rate dan 0.95 momentum.

\section{Kesimpulan}

Berdasarkan hasil dari eksperimen data diatas diperoleh Neural Network dengan class precision sebesar $87.76 \%$. Dengan prediksi masa tunggu $<=6$ Bulan sebesar 43 dan masa tunggu $>6$ bulan sebsar 6 . AUC (optimistic): 0.605 (positive class: Masa Tunggu > 6 Bulan), AUC (pessimistic): 0.605 (positive class: Masa Tunggu > 6 Bulan).

\section{Daftar Pustaka}

[1] A. Syam and A. R. Manga, "Sistem Tracer Study Alumni Fakultas Ilmu Komputer Universitas Muslim Indonesia Menggunakan Metode On-Line Analitycal Processing (OLAP)," Ilk. J. Ilm., vol. 9, no. 1, pp. 86-90, 2017.

[2] M. S. Mustafa, M. R. Ramadhan, A. P. Thenata, J. MacLennan, Z. Tang, and B. Crivat, "Data mining with Microsoft SQL server 2008," Creat. Inf. Technol. J., vol. 4, no. 2, pp. 151-162, 2018.

[3] M. A. Firdaus, A. Putra, and D. R. Indah, "Analisis Business Intelligence pada Pengelolaan Data Alumni: Upaya Mendukung Monitoring Kualitas Alumni di Perguruan Tinggi (Studi Kasus di Fakultas Ilmu Komputer Universitas Sriwijaya)," J. Generic, vol. 8, no. 2, pp. 221-229, 2014.

[4] D. H. Kamagi, "Implementasi data mining dengan algoritma c4. 5 untuk memprediksi 
Pengembangan Rekayasa dan Teknologi, Vol 16, No. 1, Juni 2020, pp 17-22

p-ISSN: $1410-9840$ \& e-ISSN: $2580-8850$

http://journals.usm.ac.id/index.php/jprt/index

tingkat kelulusan mahasiswa (studi kasus:

patterns from regulatory sequence in Drosophila

program studi teknik informatika universitas

segmentation," Nature, vol. 451, no. 7178, pp.

multimedia nusantara)," Universitas Multimedia

535-540, 2008.

Nusantara, 2014.

[5] T. Connolly and C. Begg, "A practical Approach to design, implementation, and management.” Addison-Wesley, Reading, 2005.

[7] J. Han, J. Pei, and M. Kamber, Data mining: concepts and techniques. Elsevier, 2011.

[8] binus, "Konsep Neural Network," soc.binus.ac.id, 2017.

[6] E. Segal, T. Raveh-Sadka, M. Schroeder, U. https://socs.binus.ac.id/2012/07/26/konsepUnnerstall, and U. Gaul, "Predicting expression neural-network (accessed Nov. 10, 2017). 